\title{
CORRIGENDUM
}

\section{Teaching a Student With Autism Spectrum Disorder On-Topic Conversational Responses With an iPad: A Pilot Study - CORRIGENDUM}

Cheong Ying Sng, Mark Carter and Jennifer Stephenson

http://dx.doi.org/10.1017/jse.2016.6 Published online by Cambridge University Press 13 July 2016.

In the abovementioned article by Sng, Carter, \& Stephenson, Figure 2 is incorrect. The phase change line from 'Baseline' to the 'Intervention' is cropped and in the wrong place. These two errors may mislead readers of the article.

The correct version of Figure 2 appears below. 

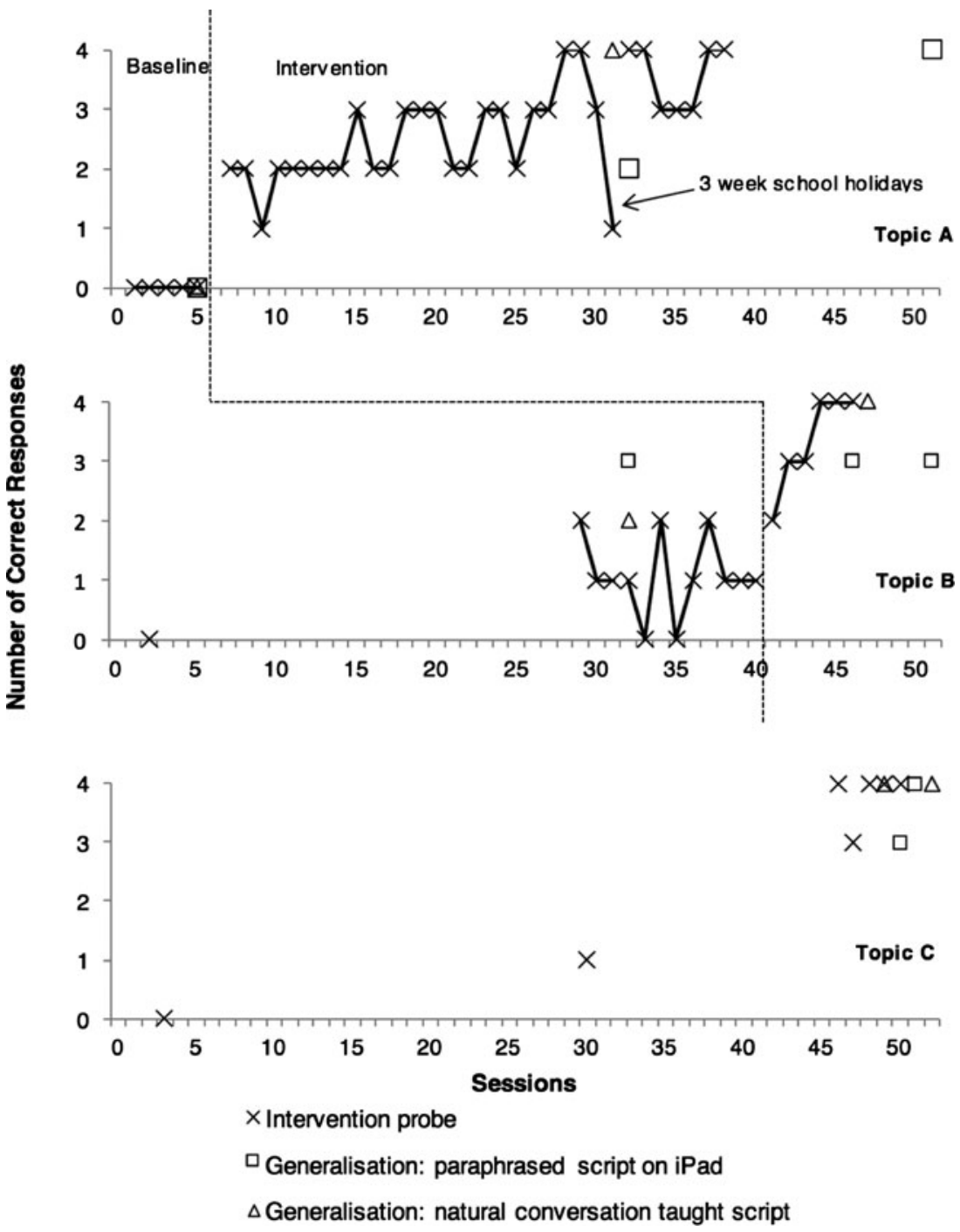

Sng, C. Y., Carter, M., \& Stephenson, J. Teaching a Student With Autism Spectrum Disorder On-Topic Conversational Responses With an iPad: A Pilot Study. Australasian Journal of Special Education. Published online 13 July 2016, http://dx.doi.org/10.1017/jse.2016.6 